\title{
The estimation of seismic risk for central Italy
}

\author{
M. Chputo, V. I. Keilis-Borok, T. I. Kroxron, G. M. Moldima, \\ G. F. Panzi, A. Pivi, Y. M. PodghetskiJi, D. Postriscint
}

Received on June 26th, 1974

Summary. - The estimation of seismic risk is made for three types of objects in the central Italy, considering three kinds of models:

1) $-\Lambda(X, g)$ : the intensity of the Poisson's flow of earthquakes, II being the magnitude, $g$ the hypocentre.

2) - $I(\bar{g}, g, M)$ : giving the distribution on the surface for a single earthquake $(g, I), g$ being the epicentre.

$3)-x(\bar{g}, I)$ : giving the effect $x$ of the shakings of intensity $I, g$ being the position of the object.

For actual decision-making additional computations may be necessary in order to estimate how our results are influenced by the errors in these models. However practical decision can be made on the basis of these data, because the experience shows that normally results are exagerated.

Riassunto. - Si effettua la stima del rischio sismico per tre tipi di oggetti nell'Italia centrale. Si considerano tre tipi di modelli: e ipocentro $g$.

1) $-\Lambda(\Lambda, g)$ : il numero annuo medio di terremoti di magnitudo $x$,

2) - $I(\bar{g}, g, \lambda)$ : la distribuzione superficiale per un singolo terremoto $(g, M), g$ indica lepicentro. dell oggetto.

$3)-x(\bar{g}, I)$ : l'effetto $x$ della scossa di intensità $I, g$ indica la posizione

Negli attuali problemi decisionali possono essere necessari calcoli addizionali per valutare l'influenza degli errori nei singoli modelli. Tuttavia decisioni pratiche possono essere prese sulla base dei risultati ottenuti, in quanto l'esperienza mostra che questi sono normalmente esagerati. 


\section{1. - INTroduction}

Dangers connected with earthquakes demand decisions on a wide variety of protective meas u res, such as bullings corles, safety regulations, special taxes, insurance etc. A problem arises to optimize these measures - all together, as a system, or at least each separately.

The rlata necessary for the solution of this problem, inclurle the estimate of seismic risk. What are the necessary estimates the units of measurement, allower errors, ete? This rlepends on a specific formulation of our problem i.e. on what kind of objects we are going to protect, what kind of damage-to prevent and what kind of protective measures-to optimize. The formulation of this problem lies outside the realm of earthquake sciences, but requires the understanding of their possibilities. The goal of this and precenling $\left(^{5}\right)$ papers is to illustrate on a concrete example the possibilities of our methor of estimating the seismic risk and to outline the set of necessary rata and their processing.

2. - THE OBJECTS AXD THE CORRESPONDING MEASURES OF SEISMIC RISK

We investigate the seismic risk for the objects of three types: areas, lines and system of points.

Areas are represented by the following 8 provinces, situated in the seismically most active part of Central Italy (Fig. 1): Frosinone, Latina, Rieti, Roma, Chieti, L'Aquila, Pescara, Termo. We consirler the territory of these provinces, their population outsicle the chief towns, and their economy. The following measures of seismic risk are calculated:

12) The part of territory, which may sulfer the shakings of intensity $I \geqslant$ VIII (in regrees of macroseismic scale).

B2) the number of people who may suffer the shakings of intensity $I \geqslant$ VIII agrees (exchuling the population of the chief towns).

C2) the economic effect of earthquakes. 


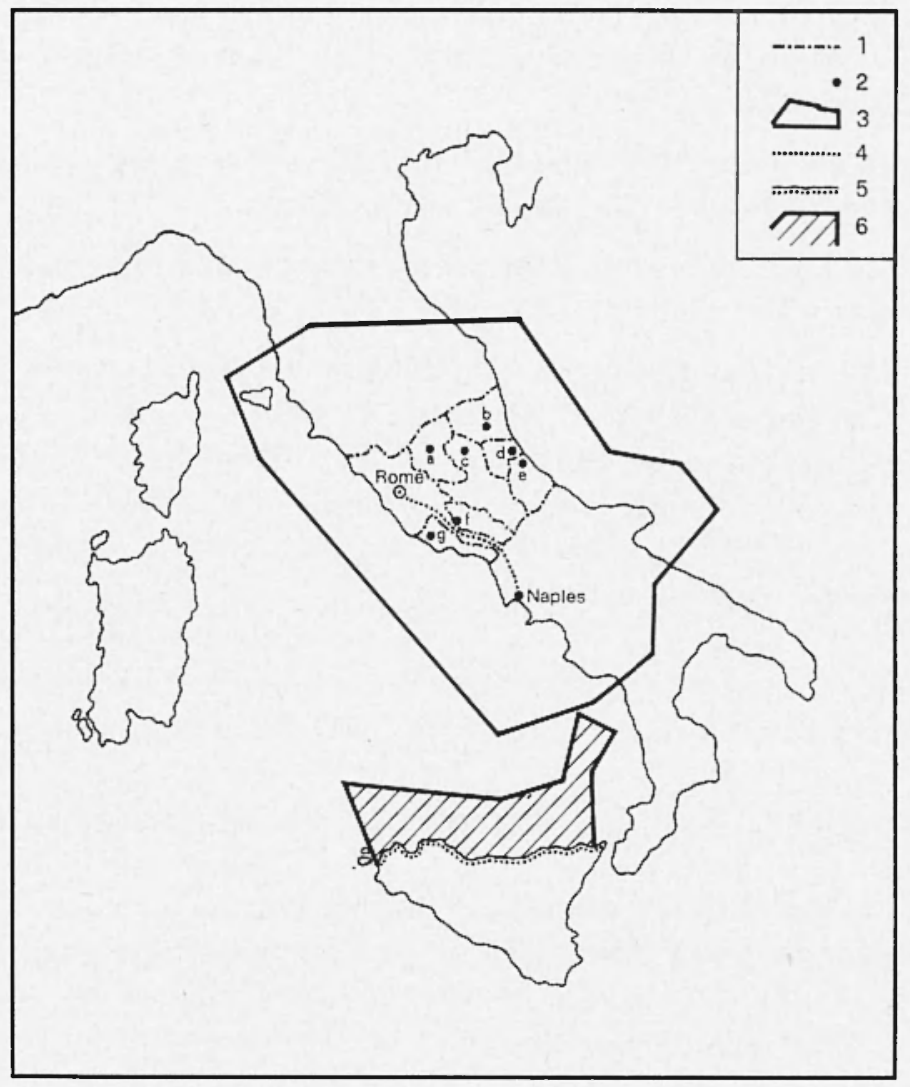

Fig. 1 - The objects, for which seismic risk was estimated.

1. Boundaries of eight provinces (variants 1-3 in Table 1): a - Rieti; b Teramo; c - L'Aquila; d - Pescara; e - Chieti; f - Frosinone; g - Latina.

2. Chicf towns of provinces.

3. Bounclaries of "danger zone": the earthquakes in this zone with $M=7$ may affect the objects 1-3.

4. Highway Rome-Naples (var. 6 in Table 1 ).

5. Northern shore of Sicily (var. 7 in Table 1 ).

6. Danger zone for Northern shore of Sicily.

Linear objects are the highway Rome-Naples $(216 \mathrm{~km})$ and the north shore of Sicily $(360 \mathrm{~km})$. For the highway we calculater the total length of such its parts, which may suffer the shakings of in- 
tensity $I=$ VIII, $I \geqslant$ VIII and $I \geqslant \mathrm{IX}$. For the shore we calculated the total length of such of its parts which may experience tsunami of conditional intensity $\geqslant 1$.

Point objects are the chief towns of the above mentioned provinces, excluding Rome. We calculated for them:

D2) the number of cities, which may happen to be in the zone of shakings of intensity $I \geqslant \mathbf{I X}$.

E2) the number of the inhabitants of these chief towns, who may suffer the shakings of intensity $I \geqslant I X$.

Each of these measures refers to a given period $T=10,30$ or 50 years. We estimated for each measure the average, dispersion and the probability distribution function. The listing of objects and computations is given in Table 1.

\section{3. - THE MODELS}

Three kinds of models are necessary for estimating the seismic risk $\left({ }^{8,10}\right)$ :

A3) - Model of the sequence of earthquakes in the volume [hypocentral zone-time-magnitude (energy)]. This model is defined by the function $A(M, g)=$ intensity of the Poisson's flow of earthquakes, $M$ being the magnitude, $g$ the point of hypocentral region $\left({ }^{0,10}\right)$.

B3) - Model $I(\tilde{g}, g, M)$, showing how the intensity $I$ of the shakings of the ground is distributed on the surface for a single earthquake $(g, M), \dot{g}$ being the point on the surface $\left(^{5}\right)$.

C3) - Model $x(\tilde{g}, I)$ of the effect $x$ of the shakings of intensity $I$ corresponding to a single earthquake, $g$ being the point of the object, $x$ the investigated measure of the seismic risk.

The parameters of all models are estimated from the observed data. Owing to the statistical nature of these data and their incompleteness, the choice of the parameters is non-unique: it is determined significantly by the particular kind of problems involved. Average values (point estimations) of parameters are preferable in such a problem, as economical prognosis or optimization of insurance. Extremal values of parameters inside their confidence limits are preferable for decision-making, concerning the safety of population, or of some exceptional objects, etc. 
TABLE 1 - SUMMARY OF THE COMPUTED PARAMETERS OF SEISMIC RISK.

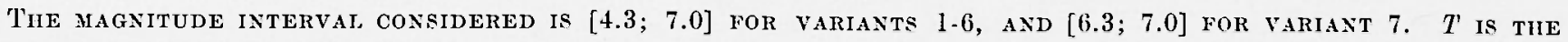
PERIOD OF TIME, IN YEARS, CONSIDERED.

\begin{tabular}{|c|c|c|c|c|c|c|c|c|c|}
\hline Variant & Object & Effect $x$ & $I$ & $T$ & $\beta$ & $m_{\Sigma}$ & $\sigma_{I}$ & $p=95 \%$ & $\begin{array}{l}\text { X. } \\
\text { reference } \\
\text { fig. or tab. }\end{array}$ \\
\hline 1 & $\begin{array}{l}\text { Territory of } 8 \\
\text { provinces }\end{array}$ & $\begin{array}{l}\text { The area of such ter- } \\
\text { ritory, which may suf- } \\
\text { fer the shaking of in- } \\
\text { tensity } I \text {, in } 1000 \mathrm{~km}^{2}\end{array}$ & $\geqslant$ VIII & $\begin{array}{l}10 \\
30 \\
50\end{array}$ & & $\begin{array}{l}1.57 \\
4.71 \\
7.85\end{array}$ & $\begin{array}{l}1.91 \\
3.31 \\
4.28\end{array}$ & $\begin{array}{r}5.1 \\
10.7\end{array}$ & $\begin{array}{l}3 a \\
3 a\end{array}$ \\
\hline 2 & $\begin{array}{l}\text { Economics of } 8 \\
\text { provinces }\end{array}$ & $\begin{array}{l}\text { The damage from } \\
\text { shakings of intensity } \\
\text { I. (mlrd. lire) }\end{array}$ & $\begin{array}{l}\text { VIII } \\
\text { IX } \\
\mathrm{X}\end{array}$ & $\begin{array}{c}10 \\
30 \\
50 \\
10 \\
30 \\
50\end{array}$ & $\begin{array}{l}0.0 \\
0.0 \\
0.0 \\
-0.03 * \\
-0.03 * \\
-0.03 *\end{array}$ & $\begin{array}{r}28.1 \\
87.4 \\
144.5 \\
25.2 \\
57.7 \\
75.5\end{array}$ & $\begin{array}{r}51.8 \\
88.7 \\
115.3 \\
44.4 \\
60.8 \\
65.2\end{array}$ & $\begin{array}{l}114 . \\
101 . \\
186 .\end{array}$ & $\begin{array}{l}3 b \\
3 b\end{array}$ \\
\hline 3 & $\begin{array}{l}\text { Population of } 8 \\
\text { provinces out- } \\
\text { side their chief } \\
\text { towns }\end{array}$ & $\begin{array}{l}\text { Number of people who } \\
\text { may happen to be in } \\
\text { the zone of shakings } \\
\text { of intensity } I \text {. } \\
10^{5} \text { people }\end{array}$ & $\geqslant$ VIII & $\begin{array}{l}10 \\
30 \\
50\end{array}$ & $\begin{array}{l}0.005 \\
0.005 \\
0.005\end{array}$ & $\begin{array}{l}1.57 \\
4.95 \\
8.67\end{array}$ & $\begin{array}{l}1.92 \\
3.50 \\
4.77\end{array}$ & $\begin{array}{r}5.4 \\
11.3\end{array}$ & $\begin{array}{l}3 c \\
3 c\end{array}$ \\
\hline 4 & $\begin{array}{l}\text { Populations of } \\
\text { the chief towns } \\
\text { of } 7 \text { provinces ** }\end{array}$ & $\begin{array}{l}\text { Number of people who } \\
\text { may happen to be in } \\
\text { the zone of shakings } \\
\text { of intensity } I . \\
10^{5} \text { people }\end{array}$ & $\geqslant I X$ & $\begin{array}{r}30 \\
50 \\
100\end{array}$ & $\begin{array}{l}0.01 \\
0.01 \\
0.01\end{array}$ & $\begin{array}{l}1.84 \\
3.46 \\
8.97\end{array}$ & $\begin{array}{r}4.24 \\
6.10 \\
12.00\end{array}$ & 8.4 & 4 \\
\hline 5 & $\begin{array}{l}\text { Chief towns of } \\
7 \text { provinees ** }\end{array}$ & $\begin{array}{l}\text { Number of chief towns } \\
\text { which suffered shak- } \\
\text { ings of intensity } I\end{array}$ & $\geqslant I X$ & $\begin{array}{r}30 \\
50 \\
100\end{array}$ & & $\begin{array}{l}0.27 \\
0.45 \\
0.90\end{array}$ & $\begin{array}{l}0.57 \\
0.73 \\
1.03\end{array}$ & 0.95 & table 6 \\
\hline 6 & $\begin{array}{l}\text { High-way } \\
\text { Rome-Naples }\end{array}$ & $\begin{array}{l}\text { T'otal lenght of parts } \\
\text { of the road, which } \\
\text { suffer the shaking of } \\
\text { intensity } I\end{array}$ & $\begin{aligned} & \text { VIII } \\
\geqslant & \text { VIII } \\
\geqslant & \text { IX }\end{aligned}$ & $\begin{array}{r}10 \\
30 \\
50 \\
100 \\
10 \\
30 \\
50 \\
100 \\
10 \\
30 \\
50 \\
100\end{array}$ & & $\begin{array}{r}11.9 \\
35.6 \\
59.3 \\
118.6 \\
14.4 \\
43.1 \\
71.8 \\
143.6 \\
2.5 \\
7.5 \\
12.5 \\
25.0\end{array}$ & $\begin{array}{r}19.1 \\
33.1 \\
42.7 \\
60.4 \\
24.7 \\
42.8 \\
55.2 \\
78.1 \\
8.7 \\
15.1 \\
19.5 \\
27.6\end{array}$ & $\begin{array}{l}42 . \\
82.5 \\
\\
\\
57.5 \\
112 .\end{array}$ & $\begin{array}{l}5 b \\
5 a\end{array}$ \\
\hline 7 & $\begin{array}{l}\text { Northern shore } \\
\text { of Sicily }\end{array}$ & $\begin{array}{l}\text { Total lenght of the } \\
\text { part of the shore af- } \\
\text { fected by tsunami of } \\
\text { conditional intensity } \\
\geqslant 1 * * *\end{array}$ & & $\begin{array}{l}10 \\
30\end{array}$ & & $\begin{array}{l}0.12 \\
0.36\end{array}$ & $\begin{array}{l}0.65 \\
1.13\end{array}$ & 3.5 & table 7 \\
\hline
\end{tabular}

* $\beta-\beta^{\prime}$ (see the text, p. 359).

** Rome (excluded in variants 4, 5), Frosinone, Latina, Rieti, Chieti, I'Aquila, Pescara, Teramo

*** (sce the text, p. 358) 
In this paper we assume average values of the parameters. Models A3) and B3) are chosen in accordance with our previous paper $\left({ }^{5}\right)$, the data on economies and population are taken from $(6,7,11)$.

Let us specify the assumed morlels.

13) - The parameters of seismicity $\left(^{5}\right)$. The function $A(M, g)$ is determined by the parameters $\alpha(g), \gamma(g)$ of the linear frequencyof-occurrence law $\left(^{5,1}\right)$. We assume for these parameters the maximum likelihood estimations, indicated in Table 2. They correspond to var. 4 in $(5$, Table 3$)$, with the following exception: the density of epicentres, and, consequently, the parameter $\alpha$ are evidently nonuniformly distributed inside the region CL. That is why this region has been subdivirled into three parts, shown in Fig. 2.

Table 3 shows, how closely our model fits the data on the known earthquakes in the interesting magnitude range. In Table $3, N_{a}$ is the number of earthquakes according to instrumental data, reduced to a period of 100 years; $N_{p}$ is the number of earthquakes in the same magnitude range, computed from the frequency-of-occurrence law with assumed values of $\alpha, \gamma$. The agreement is satisfactory. It should be noted, that the earthquakes in the $\mathbf{N}$ region do not create seismic risk for the objects considered in this paper. And the earthquakes in the $\mathbf{S}$ region create seismic (tsunami) risk only for one of these objects, that is the shore of Sicily.

B3) - The model of isoseists. The intensity of shakings is estimated in macroseismic degrees, so that model B3) is the model of isoseists. It is defined in $\left({ }^{5,2}\right)$. The isoseists are represented there by concentric ellipses. Their areas are represented by the formula:

$$
\begin{aligned}
& \lg Q(I, M)=C(I)+d M+\sigma(I) \xi \quad \text { for } M d+\sigma \xi \geqslant \varepsilon \\
& Q(I, M)=0 \quad \text { for } M d+\sigma \xi<\varepsilon \quad \text { or } M<\bar{M} \text {. }
\end{aligned}
$$

Here $Q(I)$ is the area, which suffers the shakings of intensity $\geqslant I$. $c, \pi, \sigma, \varepsilon, \bar{M}$ are the parameters of the model, $\sigma$ is the dispersion of $\lg Q, \xi$ is the random fluctuation with normal distribution $N(0,1)$ reducerl to interval \pm 3 . For a given earthquake, $\xi$ is assumed the same for all $I$. According to $\left(^{5}\right)$, $d$ depends on $I$ : we assumed however the same $d$ for all $I$; it changes the average $\lg Q$ unsignificantly, but makes the computations much faster. The parameters, assumed for computations, are given in Table 4 . 
TABle 2 - Assumed values of tire parameters of IINEar TREQUENCY-OF-OCCURRENCE LAW, REFEIS To $M=8$ [see $\left({ }^{5}\right)$, table 3 ].

\begin{tabular}{|c|r|r|r|r|r|r|}
\hline & $\mathbf{N}$ & $\mathrm{S}$ & $\mathrm{CD}$ & $\mathrm{CL}_{1}$ & $\mathrm{CL}_{2}$ & $\mathrm{CL}_{3}$ \\
\hline$\gamma$ & 0.879 & 0.807 & 0.753 & 0.822 & 0.822 & 0.822 \\
\hline$\alpha_{8}$ & -4.808 & -4.785 & -4.339 & -4.536 & -5.477 & -5.0 \\
\hline
\end{tabular}

Table 3 - Fvaluation of assuned Frequency-of-occurrence iaw: COMPARISON OF THE NUMBER OF EARTHQUAKES, ACTUALIY OBSERVED $\left(N_{a}\right)$ AND PREDICTED BY tIIS LAW, WITI PARAMETERS FROM TABLE $2\left(N_{p}\right)$.

\begin{tabular}{|c|c|c|c|c|c|c|c|c|}
\hline \multirow[b]{2}{*}{$M_{k}$} & \multicolumn{2}{|c|}{ CD } & \multicolumn{2}{|c|}{ CL } & \multicolumn{2}{|r|}{$\mathbf{N}$} & \multicolumn{2}{|c|}{$\mathbf{S}$} \\
\hline & $N_{a}$ & $N_{p}$ & $N_{a}$ & $N_{p}$ & $N_{n}$ & $N_{p}$ & $N_{a}$ & $N_{p}$ \\
\hline $4.6 \cdot 5.4$ & 58.2 & 40.7 & 82.7 & 66.0 & 22.4 & 32.1 & 46.4 & 55.7 \\
\hline $5.4-7.0$ & 11.3 & 12.7 & 24.2 & 17.7 & 4.8 & 7.6 & 9.7 & 9.6 \\
\hline 7 & 0.0063 & 0.016 & 0.0 & 0.0027 & 0.0 & 0.0026 & 0.016 & 0.0062 \\
\hline
\end{tabular}

TABLe 4 - Assumed parameters of the MOdel of isoseists. $\log Q(I, M)=C_{I}+d I I+\sigma \xi_{k}$

\begin{tabular}{|c|c|c|c|c|}
\hline$I$ & $\mathrm{X}$ & $\mathrm{IX}$ & VIII & $k=2.5$ \\
\hline$U(I)$ & -2.7 & -2.12 & -1.56 & $d=0.8$ \\
$M(I)$ & 5.8 & 5.4 & 4.2 & $\sigma=0.2$ \\
\hline
\end{tabular}




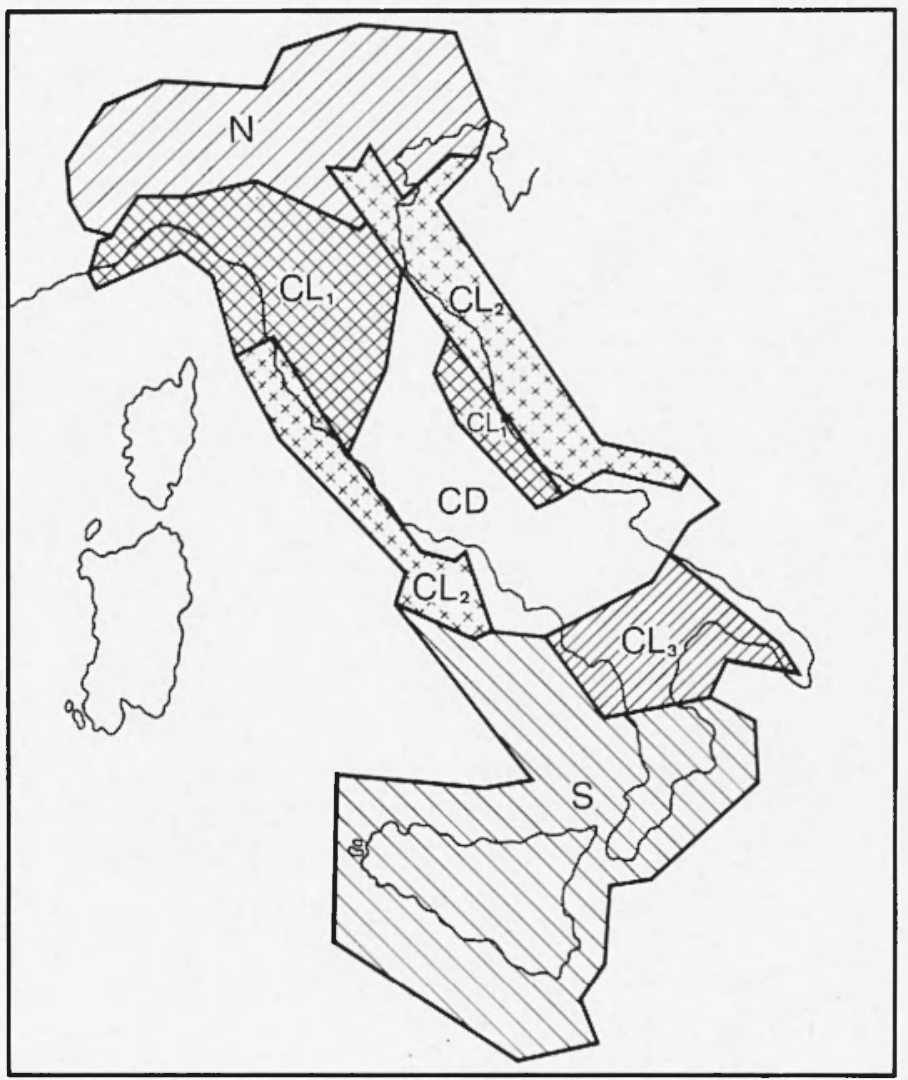

Fig. 2 - Regionalization for the earthquakes occurrence [see also $\left({ }^{5}\right)$, Figs. 1,2].

The elongation of isoseists $l$ is assumed as follows

$$
\begin{array}{ll}
l(M)=1.3 & \text { for } 4.3 \leqslant M<5.2 \\
l(M)=1.67 & \text { for } 5.2 \leqslant M \leqslant 7.0
\end{array}
$$

The azimuth A of the elongation of isoseists is assumed as follows: $A$ is the ranclom value, the same for all intensities $I$. Its distribution depends on epicentre and magnitude, but not on $I$. If the epicentre lies in the region $C D$ (i.e. near the intersection of faults) or if $M \leqslant 5.2, A$ is distributed uniformly in the whole range $\pm 180^{\circ}$. If the epicentre lies in other regions and $5.2<M \leqslant 7$, then

$$
A=A_{0}+\xi_{A} \text {. }
$$




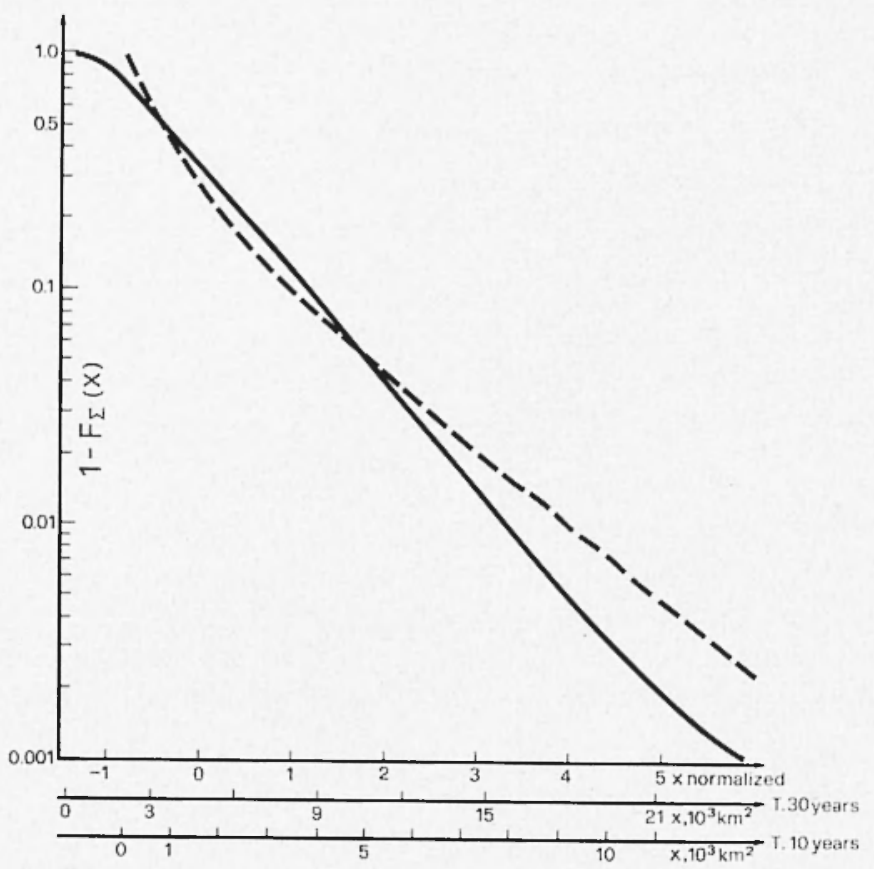

a)

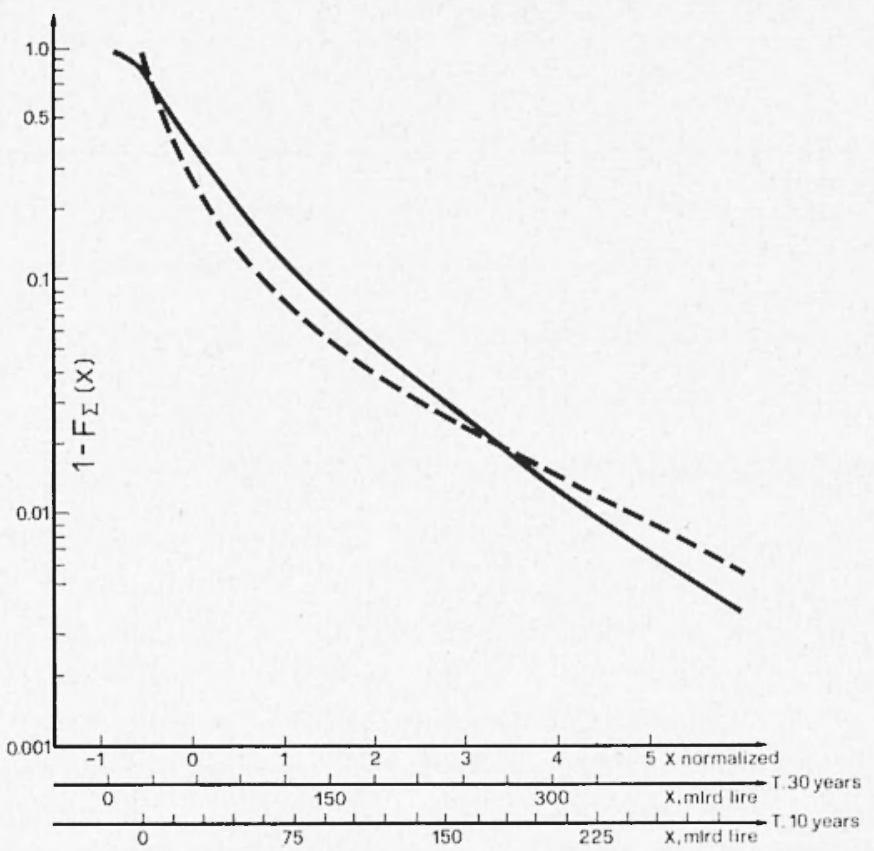




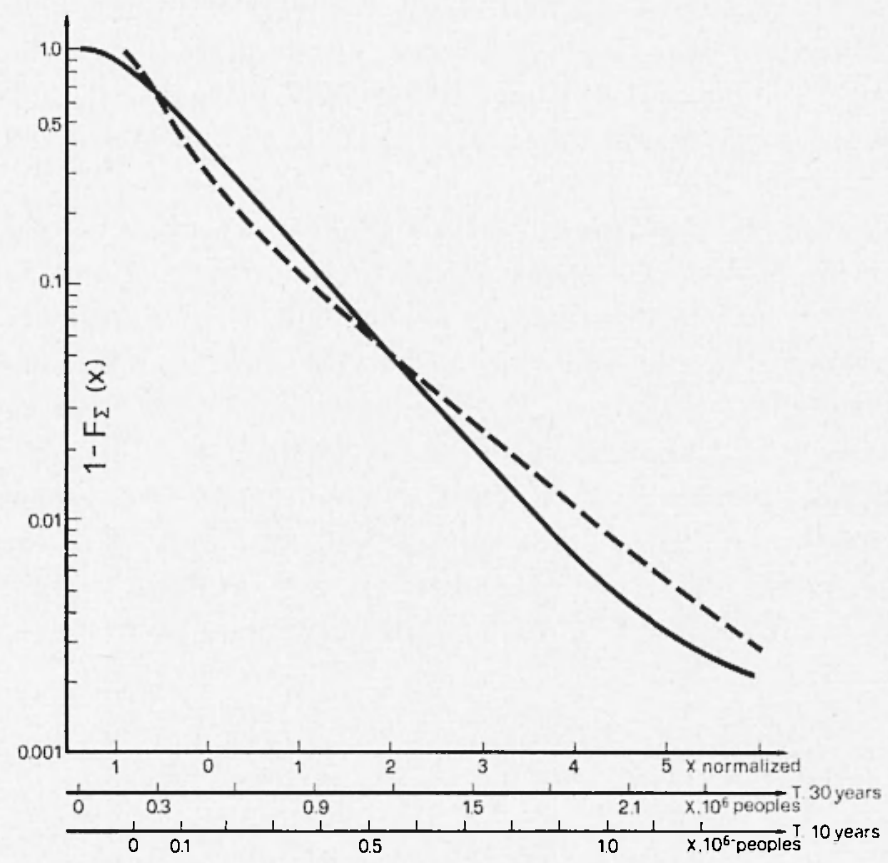

c)

Fig. 3 a, b, c - Probability distribution function of the effect of the earthquakes for 8 provinces of Central Italy.

Solid lines $T=30$ years.

Dashed lines $T=10$ years.

a) The total area of those parts of territory, which suffered the shakings of intensity $I \geqslant$ VIII (var. 1. in Table 4).

b) The economic damage in conventional units, described on page 359 (var. 2 in Table 1).

c) Population outside the chief towns of the provinees.

Here $A_{g}$ is the azimuth of the linear structure, the closest one to the epicentre; $\xi_{A}$ is the random value with discretizerl distribution $P\left\{\xi_{A}= \pm n .15^{\circ}\right\}=0.3 ; 0.22 ; 0.13$ for $n=0,1,2$ respectively.

Model of tsunami. The shores of Italy may sufter rather strong tsunami, i.e. sea waves exciter by earthquakes below the bottom of the sea. 
For a quantitative ealculation of tsunami risk additional data are necessary, on the location of the hypocentres of earthquakes, which generate tsunami and on the intensity of tsumami, considered as a function of the magnitude of the earthquake and of the epicentral distance.

Evaluation of these data for Italy requests special investigations, which are far beyond the scope of the present work. To outline the necessary data and to illustrate, how they can be used, we have done the calculations for the following conditional model, which is apparently far from the real ones. The intensity of tsunami, generated by earthquakes with magnitude 8 on the epicentral distance $800 \mathrm{~km}$, is taken as conditional unit. In these units iutensity of tsumami is assumed $\geqslant 1$ insirle the circle of radius $1 / \sqrt{\pi} 10^{0.32 M+0.5}$. The locations, where the earthquakes generate tsunami, are uniformly distributed inside the region, shown in Fig. 2, and occupy a $\mathbf{K}$-th part of this region.

\section{Population (Table j).}

For each province we take the data on population of its chief town and the average density of population outsicle the chief town. The annual increment of population is taken $1 \%$ for chief towns and $0.5 \%$ outside them. In the computation of the above mentioned density, the areas of the chief towns were allower for, in spite of its overaveraged nature. We eliminated Rome from the estimation of seismic risk referred to the population of chief towns, to make the object (the system of chief towns) not too non-uniform. The population of Rome is 5 times larger, than that of all other 7 chief towns together. To investigate such a unique object, one has to use not the averaged models of seismicity and isoseists, but local, individual models.

Economics. Three different economic measures of seismic risk have been discussed in $\left(^{8,10}\right)$; the cost of economic values, which happener to be in the zone of shakings; the total of the economic loss; the loss, prevented by the protective measures. The first two efrects are interesting in connection with problems of insurance and planning, the last one is interesting in such problems, as the choice of seismoresistant constructions.

Our computations refer to the two last measures, in conditional units. The units are determinerl, as follows: We took from (7) the lata on the cost of industrial production in each province, in per- 


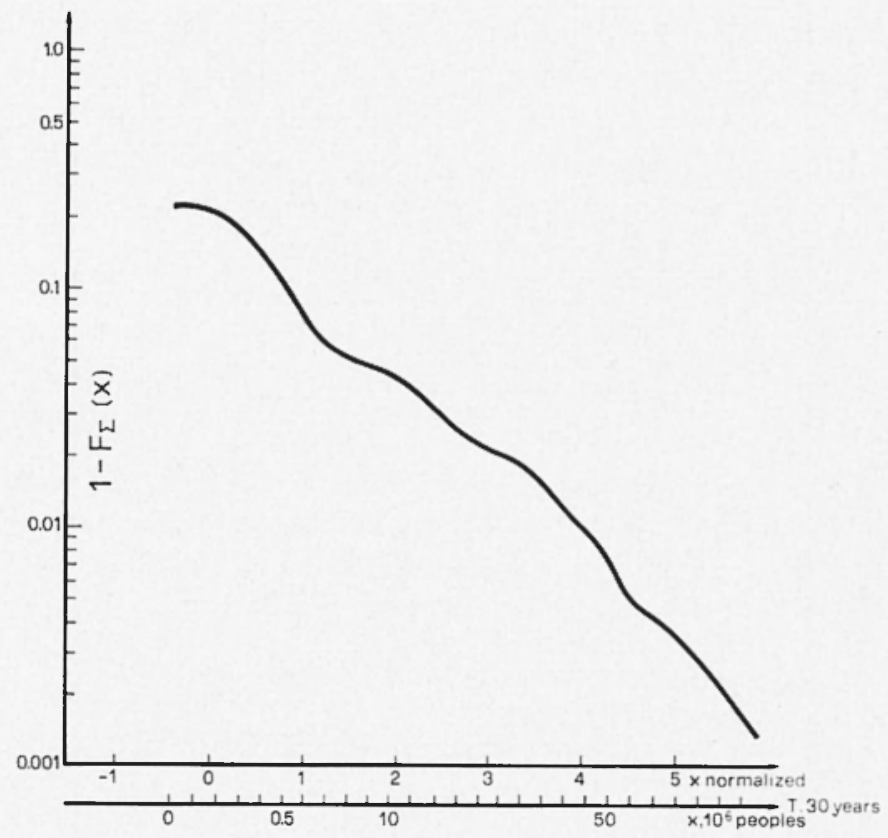

Fig. 4 - Probability distribution function for population of the chief towns of the provinces, except Rome: the number of people, who may suffer the shakings of intensity $I \geqslant I X$ during a period $T=30$ years (var. 4 in Table 1 ).

cents of the total cost of the national industrial production $R$ (see Table 5). Assuming that this cost is distributed uniformly on the territory of each province, we determined the density $\varrho$ of this cost per $\mathrm{km}^{2}$. The lack of more detailed data forced this overaveraging. Finally we assumed, that economic damages from shakings of intensity $I$ on one $\mathrm{km}^{2}$ of territory during an earthquake is proportional to $\varrho$, i.e. is equal to $R \varrho k(I)$. We take $k(\mathrm{IX})$ as a conventional unit and assume $k(\mathrm{VIII})=1 \% k(\mathrm{IX}) ; k(\mathrm{X})=k(\mathrm{IX})$. Considering $k(\mathrm{IX})$ as a total or prevented damage we can accordingly treat the results of our computations.

We reduce the damage, cansed by different earthquakes, to the common moment to the beginning of the time-period $T$. If the earthquake at the moment $t$ caused the damage $x$, then the reduced damage is $x \exp \left\{t\left(\beta-\beta^{\prime}\right)\right\}$; here $B$ is the annual rate of the increase of production, $\beta^{\prime}$ the average income from investments. In computations we assumed $\beta-\beta^{\prime}=-3 \%$ or 0 . 
Tabie 5 - Assumed data on econonics ani) population.

.

(*) $\Lambda$ t 1965 year the total cost $R$ was 14.878 .000 .000 .000 lire (7). 


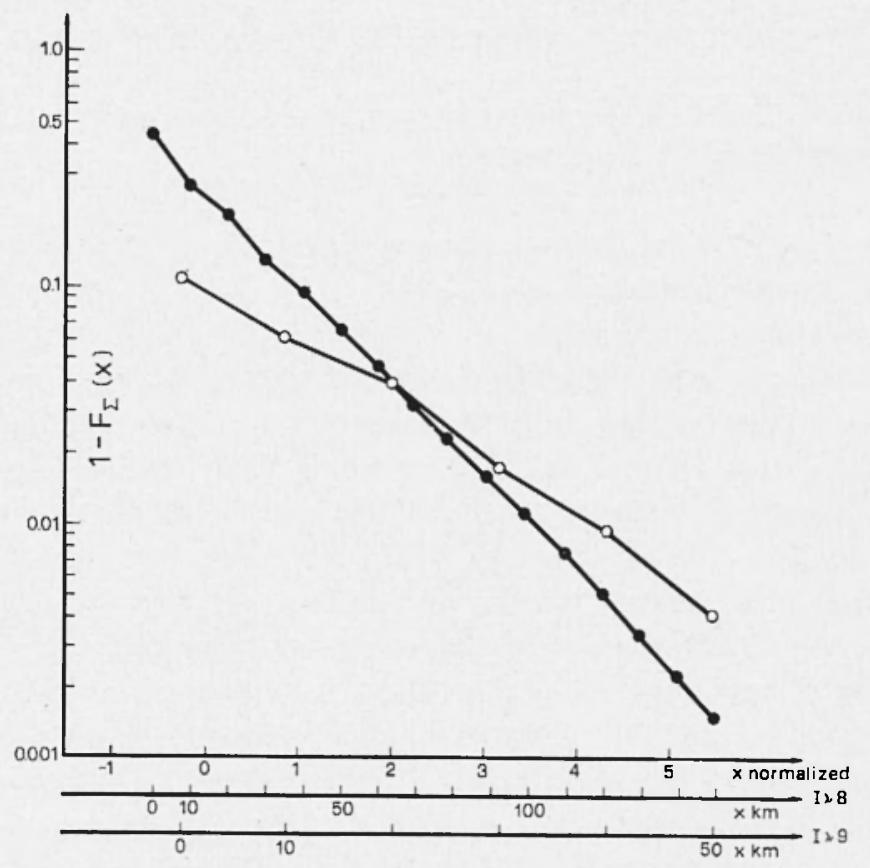

a)

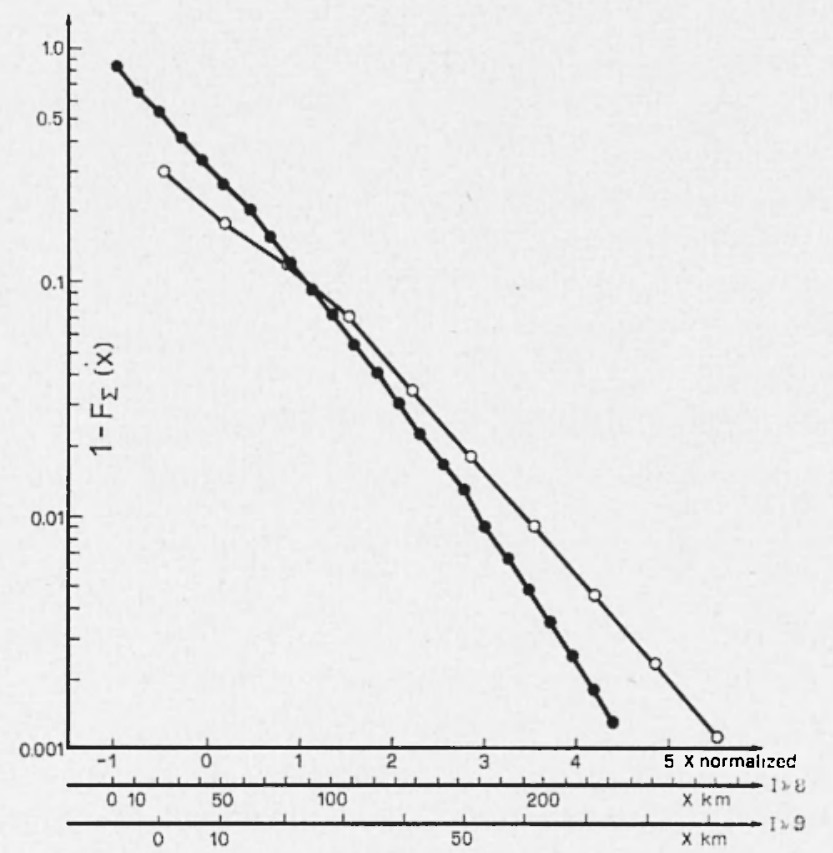

b)

Fig. 5 a, b - Probability distribution function of the effects of the earthquakes for the highway Rome-Naples the total length of such parts of the highway, which may suffer the shakings of intensity $I \geqslant$ VIII (dotter lines) and $I \geqslant I X$ (open circles lines); a) $T=30$ years; b) $T=10$ years (var. 6 from Table 1 ). 


\section{4. - Competatioxal parameters}

The algorythm of computations is described in $\left({ }^{10}\right)$. Here we shall inclicate the main parameters.

All surface coordinates of the epicentres, the boundaries of different regions and the objects were discretized. In other words, each point of the surface was assigned to the closest knot of rectangular grids with an interval $\Delta=10 \mathrm{~km}$. This interval is adequate to the averaged nature of our data on seismicity; population and economy. For control we repeated some computations with $\Delta=6 \mathrm{~km}$, after having rotated and shifted the grid etc.

The area $\mathbf{Q}$ of isoseists was discretized too. The range of magnitude was divirled into three intervals: $(4.3 \div 5.2) ;(5.2 \div 6.1) ;(6.1 \div 7.0)$. Inside each interval the range of possible values of $\mathbf{Q}$ for each $I$ was replaced by 30 evenly distributed discrete values. The control computations showed, that such a discretization of $\mathbf{Q}$ gives the upper estimation of the effects of a single earthquake: it leads to the increase of estimation of this effect by about $15 \%$.

Our final result is the distribution function of the total eflect of all earthquakes over a period $T$. This result is obtained by successive convolutions of distribution of the same effect for a single earthquake $\left({ }^{9,10}\right) ; 12$ convolutions have actually been necessary. They could be computed by asymptotic formulae only for $T=50$ years. For $T=10$ and 30 years the convolutions have been computed directly. The distribution function of the total effect of the earthquakes has been computed in the interval $\left[0 \div m_{\Sigma}+6 \sigma_{\Sigma}\right]$ where $m_{\Sigma}$ is the average effect and $\sigma_{\Sigma}$ is the dispersion.

\section{5. - Estimates of SEISMic RISK (Table 1, Figs. 3-5)}

Seismic risk is represented by the probability distribution functions $F_{\Sigma}(x)$ of different effects $x$ of the earthquakes during the timeinterval $T$. Table 1 gives the main characteristics of these functions: average $m_{\Sigma}$; dispersion $\sigma_{\underline{y}}$, the quantile $X_{\Sigma}$ of $95 \%$ confidence level $\left(X \leqslant I_{5}\right.$ with probability $\left.95 \%\right)$. Figs. $3-5$ represent the complete distribution functions. For convenience the functions $\bar{F}_{\Sigma}(x)=1-F_{Y}(x)$ are plotted. $\bar{F}_{\Sigma}(x)$ is the probability, that the eflect considered will be larger, than $x$. Two scales are given on each 
figure. The lower scale represents each effect $x$ in its natural units. The upper scale corresponds to the dimensionless effect $x_{n}=\frac{X-m_{\Sigma}}{\sigma_{\Sigma}}$ normalized in such a way, that its average is zero and its dispersion is 1 . It is interesting to note, that in dimensionless scale the distributions of different effects are much alike.

Two distributions are not plotter, but given numerically, in tables 6 and 7 . Table 6 concerns the chief towns of the 7 provinces

Table 6 - Distribution of the Number of Capitals of 7 provinces, WHICII MAY SUFFER THE SHAKINGS OF INTENSITY $\geqslant$ VIII

(var. 5 from Tahle 1).

\begin{tabular}{|c|c|c|c|c|c|c|c|}
\hline$n$ & 0 & 1 & 2 & 3 & 4 & 5 & 6 \\
\hline $100 P n$ & 77.9 & 17.8 & 3.49 & 0.62 & 0.095 & 0.013 & 0.002 \\
\hline
\end{tabular}

(except Rome). It shows, how many of these chief towns may suffer the shakings of intensity $I \geqslant$ VIII during the period $T=30$ years. $n$ is the number of such chief towns; each of them is counted as many times, as it suffered such shakings. $P_{n}$ is the probability, that the number of shakings will be equal to the value of $n$, indicated in the upper line of the table. For example, with probability $\sim 78 \%$ no chief town will suffer the shakings of $I \geqslant$ VIII from earthquakes with $M \leqslant 7$; with probability $\sim 3.5 \%$ two chief towns will suffer such shakings, etc. Table 7 shows the illustrative estimate of the eflect of tsunami. $x$ is the total length of the parts of the North shore of Sicily, which may sufler tsunami of conditional intensity $\geqslant 1$ during the time period of 30 years. $k$ is the relative area of such locations inside the hypocentral zone, in which the earthquakes generate tsunami.

\section{Conclusion}

The computations, shown in the last section, illustrate the possibility to get such estimations of seismic risk, which are complete enough to be used in decision-making. The later may concern buildings code, insurance, system of after-the-fact relief, etc. 
Table 7 - Tile total length of the parts of the North shore of Sicily, WHICI MAT SUFFER TSUNAMI OF INTENSITY $\geqslant 1$ (var. 7 from Table l, illustrative computations).

\begin{tabular}{|c|c|c|c|c|c|c|}
\hline$\frac{x}{k} \cdot(\mathrm{km})$ & 0 & 250 & 300 & 350 & 360 & 700 \\
\hline $100\left[1-F_{\Sigma}(x)\right]$ & 9.79 & 9.72 & 9.22 & 8.23 & 0.5 & 0.36 \\
\hline
\end{tabular}

For actual decision-making additional computations may be necessary; for other objects; for wider ranges of intensity of the shakings and of magnitude of the earthquakes; for other effects such as the number of people, who may be actually hurt, etc. It would be certainly necessary to repeat the computations for different variants of all models involver, in order to estimate how our results are influenced by the errors in these models and what are the error's allower. The experience shows, that the necessary accuracy of the models is often intuitively exaggerated and that many practical decisions can be made on the basis or the data already available. There is no doubt, however, that some of the models, used here (especially the models of economic efiects, population and tsunami) are insufficient.

The goal of this paper will be achieved if it will stimulate the formulation of concrete proposals of optimization on seismic protective measures, with specification of the objects to be protected and of the kind of parameters to be considered. According to such a formulation the appropriate morlels conld be constructed and adequate estimates of the seismic risk then computed.

\section{REFERENCES}

(1) Algermissen et al., 1969. - Studies in seismicity and earthquake damage statistics, Summary and recommendations; Appendix A, Appendio $B$. US Dept. of Commeree. USA.

(2) Borges 1. F., Castanimeta M., 1971. - Structural Safely. Lysbon.

$\left({ }^{3}\right)$ Boschi li., Caputo M., Panza G. F., 1968. - Stability of seismic activity in Italy with special reference to Garjagnana, Mugello and Forlivese. CNEN, R'T/ING (69) 24. 
(4) Caputo M., Chinini A., Pieri L., 1968. - Statistical evaluation of earthquakes in three sites, proposed for a nuclear plant. CNEN, $\mathrm{RT} / \mathrm{ING}(69)$, 14.

(5) Caputo M., Keilis-Borok V. I., Kronrod T. L., Molchan G. M., Panza G. F., Piva A., Podgaetskaja V. M., Postpiscill D., 1973. Models of earthquake occurrence and isoseismals in Italy. "Annali di Geofisica”, XXVI (2-3), pp. $421-444$.

${ }^{8}$ ) Carta della densità della popolazione in Italia (Cens. 1951), 1960. Scala $1: 1.500 .000$, Firenze.

(7) I conti provinciali e regionali, 1965. - Moneta e Credito, Roma.

(8) Kantorovicit L. V., Keilis-Borok V. I., Molchan G. M., 1973. Probability principles of seismic zoning and estimation of seismic risk (in Russian). "Vichislitelnaya seismologia", 6, Moscow, Nauka.

$\left({ }^{9}\right)$ Molchan G. M., Keilis-Borok V. I., Vilkovicil G. V., 1970. - Seismicity and principal seismic effects. "Geopl. J. R. Astr. Soc.", 21.

(10) Molcilan G. M., Keilis-Borok V. I., Kronrod T. L., 1973. - Algorythm for estimation of seismic risk (in Russian). "Vichislitelnaya Seismologiya", 6, Moscow, Nauka.

(11) Strade, autostrade d'Italia AGIP, 1970. 